\title{
A Case Study in Systematic and Methodical Design Engineering
}

\author{
W. Ernst Eder and Patrick J. Heffernan \\ Royal Military College of Canada \\ eder-e@kos.net
}

\begin{abstract}
At RMC, in Mechanical Engineering, the third-year course MEE 303 'Principles of Engineering Design' consists of 12 lectures and two mini-projects, one for redesign, and one for novel design. The redesign alternates between a water valve and an automotive oil pump. This case study is now up-to-date according to the most recent developments in the theoretical framework that is the basis for the systematic and methodical process. The search for solutions in this process involves creativity supported by systematic working.

An automotive oil pump is to be redesigned for revised conditions. The existing oil pump originated from the 1970 's, and was used in a V-8 engine. A reconstituted set of engineering drawing was prepared. Using the recommended systematic procedure, and other appropriate methods, students were asked to perform the redesign process: to develop a design specification, to analyze the existing pump to detect organs and functions, to explore the solution field with a morphology, and to suggested an improved embodiment. The case study as presented here serves as a sample solution.
\end{abstract}

\section{Introduction}

At the Royal Military College of Canada, in the Department of Mechanical Engineering, the third-year course MEE 303 'Principles of Engineering Design' has been operated since 1992. The course consists of 12 lectures (one per week) on theories and principles for design. In addition, two mini-projects are used, one for redesign, and one for novel design (two periods per week). The redesign alternates between a water valve [1] and an automotive oil pump. This case study was previously presented in a preliminary form at the 2006 CDEN Conference [2]. It is now brought up-to-date according to the most recent developments in the theoretical framework $[3,4,5,6,7]$ that is the basis for the systematic and methodical process. The search for solutions in this process involves creativity supported by systematic working.

The first case study using this systematic process according to the state of the theory and method at that time, appeared in 1980 [8] - a welding positioner. The next three, also systematic, were published in 1981 [9] - a riveting fixture, a milling jig, and a powder-coating machine. The third set was published in 1983 [10], a P-V-T-experiment, a hand winding machine for punched tapes, and a tea brewing machine - the first two were systematic, the third took a more industrialartistic design approach. An English edition was published in 1988 [11], and included the existing six case studies $[9,10]$, plus two new items - a wavepowered bilge pump, and an oil drain valve - and again the bilge pump only loosely followed the systematic method. Three further case studies were published in 2008 [3] - the tea machine now revised to conform to systematic procedures according to the state of the theory and method at that time, delivering much enhanced engineering information; re-design of a water valve; and an electro-static smoke gas dust precipitator, with subsidiary rapper for dust removal. An automotive oil pump is to be redesigned for revised conditions. The existing oil pump originated from the 1970's, and was used in a V-8 engine. A cutaway and a loosely assembled pump were supplied to the students, for them to be able to compare the tangible parts with a reconstituted set of engineering drawings. Using the recommended systematic procedure, and other appropriate methods, students were asked to perform the redesign process. They first needed to develop a design specification. Their next task was to analyze the existing pump to detect organs and functions. They then explored the solution field with the help of a morphology, and suggested an improved embodiment to fit more modern conditions. The case study as presented here serves as a sample solution, given to the students after their own attempts have been completed.

These cases have been edited to show the final results after iterations, recursions, revisions, trial starts and corrections from later steps of the design process. Such trials would have made the cases too long. The 
cycle at the end of each major section is therefore indicated, but not detailed.

\section{Case Study - Oil Pump}

The assembly drawing is shown in figure 1 .

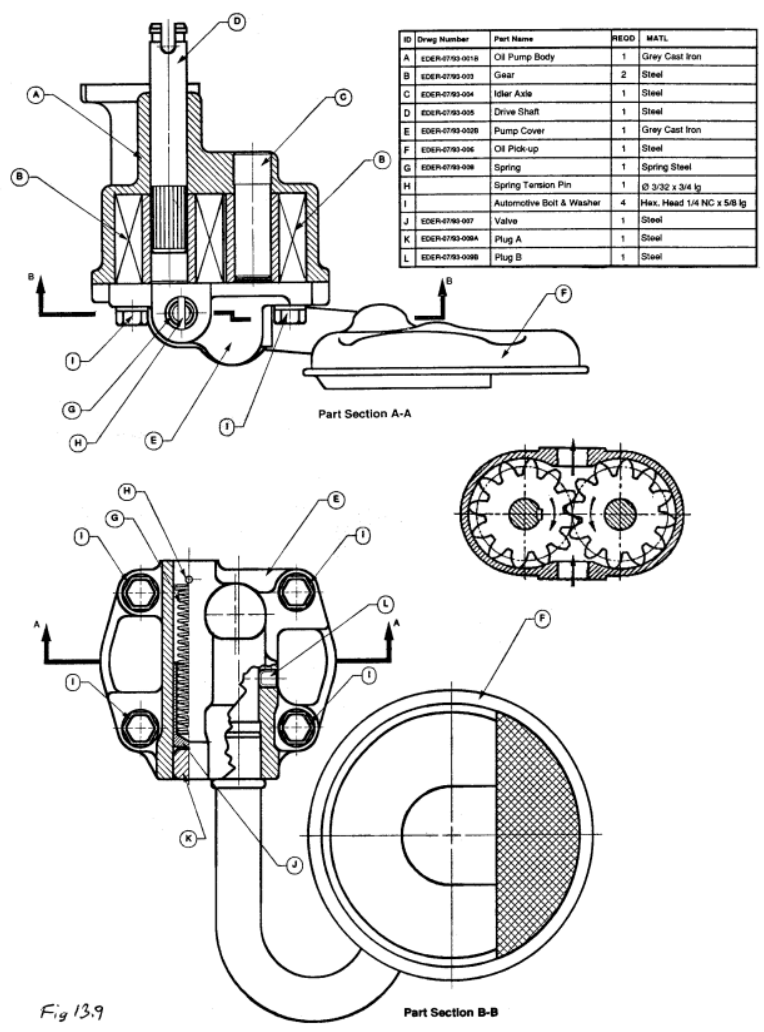

Figure 1 Existing Oil Pump

\section{(P1) Establish List of Requirements - investigate alternatives}

Requirements are listed only under the most relevant Transformation Process (TrfP) and/or Technical System (TS) property as judged by the engineering designer, and cross-referenced if they are repeated in any other relevant property class. Indication of priority - F ... fixed requirement, must be fulfilled; $S$... strong wish; W ... wish; N ... not considered.

\section{$R q 1 \quad O r g R q$ Organization requirements None.}

$R q 2 \quad T r f R q \quad$ Requirements of the Transformation F Retrieve oil from engine sump, pressurize, and deliver to engine oil channels. Note that such a pump will deliver a flow rate of oil, the pressure at the pump is caused by the flow resistance in the engine oil channels and bearings.
$R q 3 \quad E f R q \quad$ Effects requirements of the TS

Rq3A FuRq Function requirements - behavior

F Provide $\mathbf{x}_{\mathbf{1}} \mathrm{m}^{3} / \mathrm{min}$ flow of oil at $\mathbf{y}_{\mathbf{1}} \mathrm{kPa}$ pressure (idling speeds).

F Provide $\mathbf{x}_{\mathbf{2}} \mathrm{m}^{3} / \mathrm{min}$ flow of oil at $\mathbf{y}_{\mathbf{2}} \mathrm{kPa}$ pressure (intermediate to high rotational speeds).

$\mathrm{F} \quad$ Regulate maximum oil pressure to $\mathbf{p} \mathrm{kPa}$.

Rq3B FuDtRq Functionally determined requirements - conditional on TS(s) operating

F Operate using rotational energy obtained

from the engine camshaft (given location and sizes).

F Accommodate 10W30 (or similar) oil specification at all working temperatures, typically $40^{\circ} \mathrm{C}$ to $+60^{\circ} \mathrm{C}$ ambient air.

F Strain oil, maximum particle size into pump $0.5 \mathrm{~mm}$ spherical.

F Self-priming, when pump contains air in the operand spaces, back-leakage low enough to provide suction for oil.

S Positive displacement, some pumping at any low rotational speed.

F Lift oil from sump $\mathbf{x}$ m below pump body.

$R q 3 C \quad O p p R q$ Operational requirements

$\mathrm{S} \quad$ Continue to function adequately for approximately $\mathbf{x}$ years (assume conditions of service).

F Overall volume of new pump should not exceed $\mathbf{x} \mathrm{m}^{3}$.

F Weight should not exceed $\mathrm{x} \mathrm{kg}$.

$\mathrm{W}$ Accommodate placement of pump a maximum $\mathbf{x} \mathrm{m}$ from oil source.

W Accommodate parts replacement in $\mathrm{x}$ hrs by qualified technician.

W Operate on e kW or less (efficiency statement).

$R q 4 \quad M f g R q \quad$ Manufacturing requirements

F Minimize cost of manufacture using

equipment available on site and with outside suppliers. Specify in more detail which costs (life cycle) should be reduced (indirect Fixed Costs or direct costs variable), etc.

$R q 5 \quad D i R q$ Distribution requirements

S Packed into bulk box for OEM, packed into individual box for spares.

Rq6 LiqRq Liquidation requirements

$\mathrm{S} \quad$ All materials recyclable

Rq7 HuFRq Human factors requirements

F No sharp edges on assembled unit.

F Sufficient clearances for wrenches for maintenance.

$R q 8 \quad T S F R q$ Requirements of factors of other TS (in their $\operatorname{Trf} P$ )

F Use standard tools and wrenches only.

$R q 9 \quad$ EnvFRq Environment factors requirements, LC1 - LC7

$\mathrm{F} \quad$ Seal against oil leakage. 
Rq10 ISFRq Information system factors requirements, LC1 - LC7

$\mathrm{S} \quad$ Offer size range of pumping capabilities in geometric progression.

Rq11 MgtFRq Management factors requirements

$\mathrm{S} \quad$ Quality Assurance plan? (imposed by OEM, ISO 9000 registration)

DesRq Engineering design requirements for $\operatorname{TrfP}(s)$ and $T S(s)(R q 12-R q 14)$

None.

P1.8 \{Improve, optimize $\quad<$ Substantiate, evaluate, select, decide $>\quad\{$ Verify, check, reflect $\}$

\section{(P2) Establish a Plan for the Design Work - investigate alternatives}

Modify systematic procedure from [3].

No difficulty anticipated, guide students in application of design process.

Four weeks ( 3 hours per week) as target for project. Precedents were available in the literature (a) for operation of design case studies, (b) for automotive oil pumps.

P2.8 $\quad$ Improve, optimize $\} \quad<$ Substantiate, evaluate, select, decide $>$ \{Verify, check, reflect $\}$

\section{(P1Rev) Amend Design Specification for New Requirements:}

F Oil pump must be relocated outside of crank case.

S Strainer and suction pipe remain inside crankcase / oil pan.

F All parts easily accessible for repair.

W Appearance is now a criterion.

(P3a) Establish the Transformation Process investigate alternatives

See figure 2 .

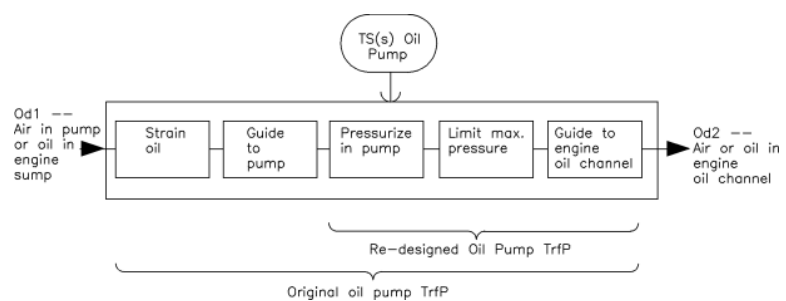

Figure 2 Oil Pump - Transformation Process

PROCEDURAL NOTE: For a re-design problem, the TrfP as in figure 2 is not really required, but can add to understanding.

\section{(PRev5) Establish the Existing TS-Organ Structure by Reverse Engineering}

The revised design process starts from the existing assembly drawing, figure 1 . This was first transformed into a 'skeleton' representation, ignoring all material wall-thicknesses, see figure 3 - an organ structure. The revised boundary of the new TS(s) is also indicated.

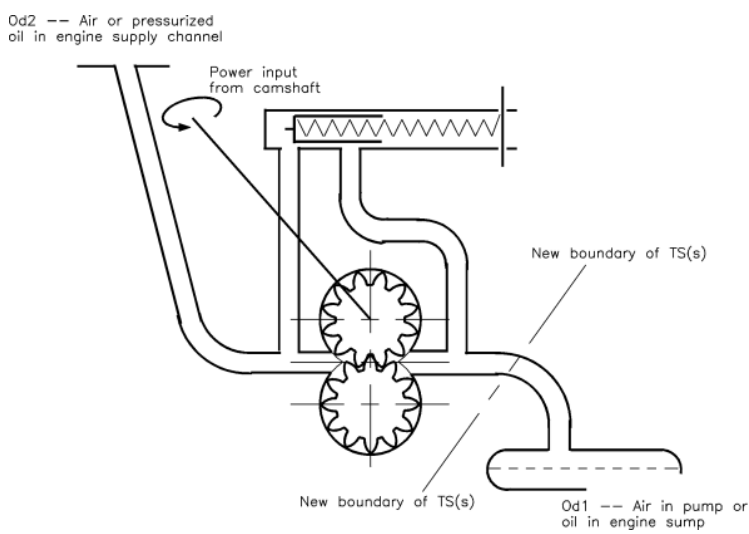

Figure 3 Oil Pump - Organ Structure

\section{(PRev4) Establish the Existing TS-Function Structure by Reverse Engineering}

By searching for significant contacts in both the assembly drawing or TS-constructional structure, and the TS-organ structure, figures 1 and 3, (a) between surfaces on adjoining constructional parts, (b) on constructional parts with the operand, and (c) with the active and reactive environment, elemental organs together with their elemental functions, and organ groups could be identified.

PROCEDURAL NOTE: As a designer becomes more experienced, the typical organ structure of figure 3 is no longer needed, the organ groups can be 'read' directly from the TS-constructional structure.

Additional symbols (parts letters are shown in the parts list, figure 1):

$\mathrm{O}$ - Oil operand

$\mathrm{X}$ - Engine driving power supply

Y - Crankcase attachment flange

For the revised design specification, the following were no longer needed, they remain within the crankcase as constituent parts of the engine:

O1-F Oil in sump to pick-up

- collect and strain oil

F-E Oil pick-up to cover

- form guide for oil into cover 
By inspection, the following were recognized as organs that were evoked by manufacturing requirements, they do not need to be considered for a revised TS-function structure:

B1-D Gear bore to drive shaft

- transmit driving torque, mfg auxiliary, press

fit

C-A Idler axis to body

- mfg auxiliary, press fit

E-L Plug for transfer port mfg auxiliary, through drilling

E-K Plug for valve guide - mfg auxiliary, through boring

A-E Cover to body - seal against outward leakage $\quad$ OGa

A-E-I Cover to body fastening - hold parts together

Connections to the fixed system 'engine' were found:

A-Y Body to crankcase attachment - hold parts together

A-Y-O2 Body to crankcase oil channel - allow transfer of pressurized oil

O1-Y-A Crankcase oil channel to body - allow transfer of sucked oil

D-X Drive shaft slotted end - accept torque and rotation

The organ grouping OG1 reflects the requirements for the revised oil pump.

Elemental organs were selected to form a typical organ group:

A-B Body flat bore face to gear face - seal against back leakage

A-B Body cylinder to gear tooth tip - seal against back leakage

E-B Cover flat face to gear face - seal against back leakage

B1-B2 Gear tooth mesh - seal against back leakage

A-B-E Gear tooth gap, flanks and root - package oil for transport

The appropriate TS-functions for this group are: Fu1 - "isolate a series of volumes that can be rotated from an input space to an output space", and Fu2 - "adequately reduce back-leakage".

J-E Valve to cover guide - seal against outward leakage $\quad$ OG4

J-E Valve to cover guide - allow axial movement

O2-J Oil to valve head - transform oil pressure to force
J-E Valve to cover transfer port - open/close oil by-pass

$\mathrm{J}-\mathrm{G} \quad$ Valve to spring

- transfer axial force

$\mathrm{G}-\mathrm{H} \quad$ Spring to pin - react spring force to cover

H-E Pin to cover - retain valve and spring

The appropriate TS-functions for this group are:

Fu3 - "sense operand-space pressure"

Fu4 - "move sensor proportionally"

Fu5 - "at pressure limit, open by-pass port to allow operand into entry space"

Fu6 - "seal against outward leakage"

The other organ groups were identified by inspection, without specifying the elemental organs:
$\mathrm{X}-\mathrm{D} \quad$ Drive in engine to shaft end
- accept torque and rotation
OG5
D-B1 Shaft end to driving gear
- transmit torque and rotation
OG6
D-A Driving gear shaft to body
- locate shaft in body
OG7
B1-B2 Driving gear to idler gear - transmit force and rotation OG8
B2-C-A - locate idler in body
OG9
E-A Cover to body
- transfer oil to gear mesh entry
OG10

TS-functions for these organ groups were formulated. The TS-function structure for the revised oil pump is shown in figure 4.

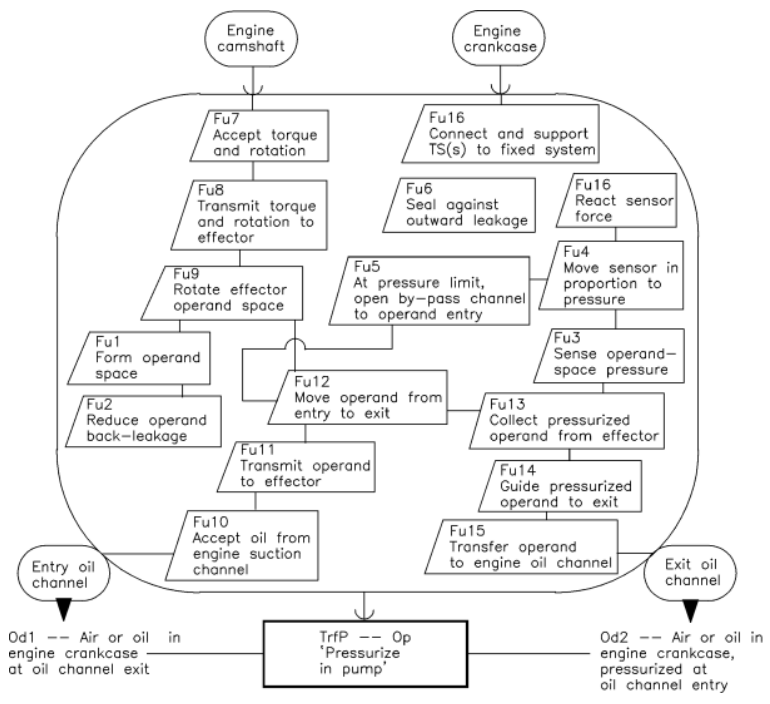

Figure 4 Oil Pump - Function Structure 
P3.5 $\quad$ Improve, optimize $\} \quad<$ Substantiate, evaluate, select, decide $>$ \{Verify, check, reflect $\}$

\section{(P4) Establish the TS(s)-Organ Structure - investigate alternatives}

In essence, only three TS-function groups need to be explored for alternatives, Fu12, and the groups of $\mathrm{Fu} 3 / \mathrm{Fu} 4 / \mathrm{Fu} 5$ and Fu11/Fu13. A formal morphological matrix is probably not needed. Systematic sub-division helped to make the survey as complete as practicable.

\section{Fu12 Move operand (air or oil) from entry to exit TgPc1 Two external gears}

(A) Involute, $\mathrm{n}_{\min }=9$ when corrected to avoid undercuts

(a) straight, see figure 5, part A

(b) helical

(B) Involute, undercut, $\mathrm{n}=2$ or 3 teeth, Rootsblower style

(a) straight, see figure 5, part B

(b) helical

(C) Non-involute, symmetrical or unsymmetrical conjugate

(D) Steep spiral/screw L.> 1.2 pitch, see figure 5, part $\mathrm{C}$, involute, non-involute (symmetrical or unsymmetrical conjugate), or screw thread form

\section{TgPc2 External plus internal gear}

(A) Involute, $\mathrm{n}_{\min }=8$ external, $\left(\mathrm{n}_{\min }+1\right.$ or 2$)$ internal

(a1) straight, internal gear with root gaps, see figure 5, part D

(b1) helical, internal gear with root gaps

(a2) straight, end entry, see figure 5, part E

(b2) helical, end entry

(B) Non-involute lobed internal $(3,4,5$ or 6 indentations) and external (2, 3, 4 or 5 protrusions) rotors, see figure 5 , part $\mathrm{F}$

\section{TgPc3 Radial vanes}

(A) Flat radially sliding plates, see figure 5, part G

(B) Flexible vanes, see figure 5, part $\mathrm{H}$

(C) Liquid outer boundary (kept in place by centrifugal action), vanes dip in

\section{Fu11 Transmit operand to effector}

Ful3 Collect operand from effector

(A) Radial entry

(B) Axial end-entry

Fu3 Sense operand pressure

Fu4 Move sensor proportional to pressure

Fu5 At pressure limit, open by-pass channel to operand entry

(A) Cylindrical piston, side by-pass opening, see figure 5, part J

(B) Spherical closure element, side by-pass opening, see figure 5 , part $\mathrm{K}$
(C) Plate closure over by-pass opening, pre-loaded to pressure limit, see figure 5, part L (solution to $\mathrm{Fu} 4$ is "none")

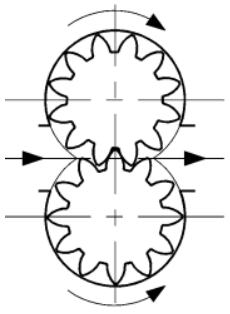

(A) Gear Pump
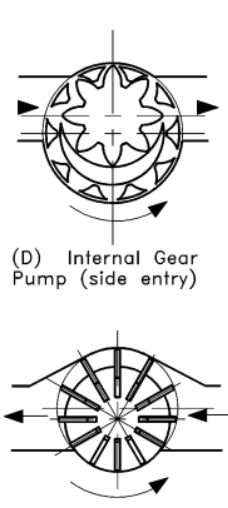

(G) Vane Pump

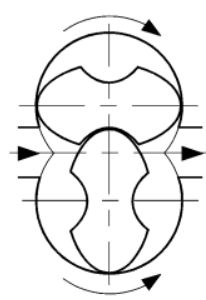

(B) Undercut Gear Pump (Roots)
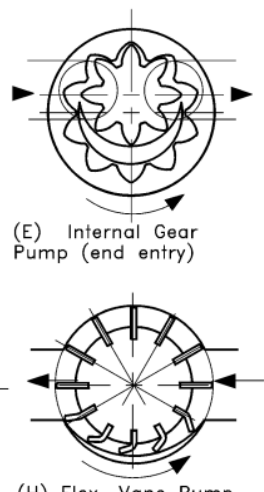

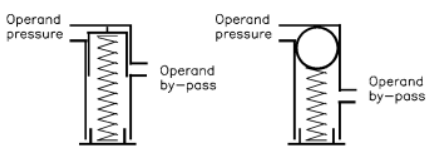

(J) Cyl. Piston

(K) Sphere closure

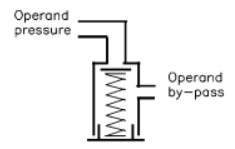

(L) Plate closure

[iteroture Wankel, F., Rotary Piston Machines, London: Iliffe, 1965

Figure 5 Oil Pump -- Morphology

P4.11 \{Improve, optimize $\}<$ Substantiate, evaluate, select, decide $>$ \{Verify, check, reflect $\}$

The most compact arrangement promises to be Fu12TgPc2-(B) with 4 lobes external into 5 lobes internal, Fu11/Fu12-(B), and Fu3/Fu4/Fu5-(A), see figure 6.

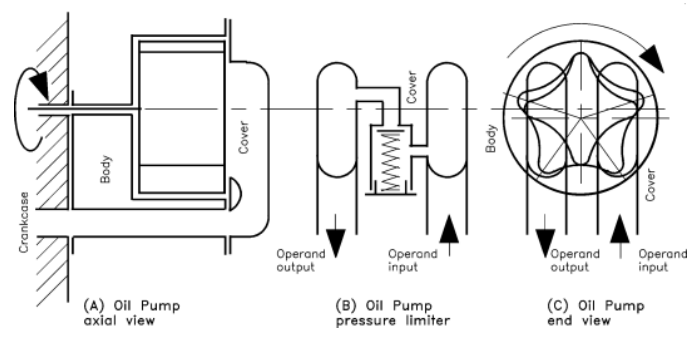

Figure 6 Oil Pump - Revised Organ Structure 


\section{(P5a) Establish the Constructional Structure (1) - investigate alternatives}

Making the body and the cover as aluminum diecastings can provide the oil channels in the easiest way, with minimal machining.

The subsequent stages and steps from [3] appear to be routine design work for design engineering. We have chosen not to complete these stages and steps. Nevertheless, the importance of these subsequent steps must be emphasized, as many fault conditions may unintentionally be introduced in the embodiment and detail phases.

\section{Closure}

This length of paper does not allow a fuller discussion of the recommended method. Within the third-year course MEE 303, students are given the relevant background information in lectures with hand-out notes. They work in groups of three or four on this mini-project, under the guidance of the professor with frequent reference to the lecture notes, step by step with as little iteration as necessary. Reviews and reflection are encouraged. The proof of usefulness of this approach, in our opinion, is that in their final-year projects students frequently use and report some sections of methods used for this design process. Especially the concept of morphology is often used to explore candidate solutions to their problems.

\section{References}

[1] Eder, W.E. (2006) 'Case Study in Design Engineering' in Proc. CDEN 06 Toronto, 24-26 July 2006, on CD-ROM

[2] Heffernan, P.J. and Eder, W.E. (2006) 'Redesign an Oil Pump', CDEN 06 Toronto, 24-26 July 2006, presentation only

[3] Eder, W.E. \& Hosnedl, S. (2008) Design Engineering: A Manual for Enhanced Creativity, Boca Raton: CRC Press

[4] Eder, W.E. (2008) 'A Case for Systematic and Methodical Design Engineering', in Proc. CDEN 08, Halifax, N.S., 27-29 July 2008, on CD-ROM

[5] Eder, W.E. (2008) 'Aspects of Analysis and Synthesis in Design Engineering', in Proc. CDEN 08, Halifax, N.S., 27-29 July 2008, on CD-ROM

[6] Eder, W.E. (2008) 'Requirements to Properties Iterative Problem Solving', in Proc. AEDS 2008 Workshop, 31 October - 1 November 2008, Pilsen - Czech Republic: University of West Bohemia, p. 49-65
[7] Eder, W.E. (2008) 'Competency and Expertise in Design Engineering', in Proc. AEDS 2008

Workshop, 31 October - 1 November 2008, Pilsen - Czech Republic: University of West Bohemia, p. 67-74

[8] Hubka, V. (1982) Principles of Engineering Design, London: Butterworth Scientific, (translated and edited by W.E. Eder from Hubka, V. (1980) WDK 1 - Allgemeines Vorgehensmodell des Konstruierens (General Procedural Model of Designing), Zürich, Heurista; translated into several other languages: French, M. Wyss (1980) Zürich: Heurista; Italian, U. Pighini (1982) Marsilo ed.; Czech, S. Hosnedl (1995) Zürich: Heurista, and others

[9] Andreasen, M.M., \& Hubka, V. (1981) WDK 4a: Methodisches Konstruieren von Maschinensystemen - Fallbeispiele (Systematic Designing of Machine Systems - case examples), Zürich: Heurista

[10] Hubka, V., Andreasen, M.M., \& Eder, W.E. (1983) WDK 4b: Methodisches Konstruieren von Maschinensystemen - Fallbeispiele (Systematic Designing of Machine Systems - case examples) Zürich: Heurista

[11] Hubka, V., Andreasen, M.M., \& Eder, W.E. (1988) Practical Studies in Systematic Design, London: Butterworths

W. Ernst Eder,

Professor Emeritus (Royal Military College of Canada),

Dr h.c. (University of West Bohemia in Pilsen) Home (normal mailing address): 107 Rideau Street, Kingston, Ontario, Canada K7K 7B2

Phone 1-613-547-5872, eder-e@kos.net 